\title{
The positive impact of surgeon specialization on survival for gastric cancer patients after surgery with curative intent
}

\author{
Yuexiang Liang $\cdot$ Liangliang $\mathrm{Wu} \cdot$ Xiaona Wang $\cdot$ \\ Xuewei Ding $\cdot$ Han Liang
}

Received: 17 May 2014/Accepted: 5 October 2014/Published online: 15 October 2014

(C) The International Gastric Cancer Association and The Japanese Gastric Cancer Association 2014

\begin{abstract}
Background Many studies have affirmed the survival benefit for cancer patients treated by specialized surgeons. Methods A total of 967 patients with gastric cancer (GC) who underwent gastrectomy with curative intent in our center were enrolled. Patients were categorized into two groups based on surgeon specialization: the specialized group (SG) and nonspecialized group (NSG). To overcome bias due to the different distribution of covariates for the two groups, a one-to-one match was applied using propensity score analysis. After matching, prognosis and recurrence data were analyzed.

Results After one-to-one matching, 261 patients in the SG and 261 patients in the NSG had the same characteristics excluding factors associated with surgery. In multivariate analysis for the whole study series, surgeon specialization was an independent prognostic factor for GC patients after surgery. Patients in the SG demonstrated a significantly higher 5-year overall survival than those in the NSG (50.7 vs. $37.2 \%, p=0.001)$. With the strata analysis, significant prognostic differences between the two groups were only observed in patients at stage IIIa-b or N1-2. The proportion of locoregional recurrence was greater in the NSG than in the SG.

Conclusion GC patients treated by specialized surgeons tended to have a better prognosis and lower locoregional recurrence rate. Surgeon specialization was an independent
\end{abstract}

Y. Liang and L. Wu contributed equally to this work.

Y. Liang $\cdot$ L. Wu $\cdot$ X. Wang $\cdot$ X. Ding $\cdot$ H. Liang $(\bowtie)$ Department of Gastric Cancer, Key Laboratory of Cancer Prevention and Therapy, National Clinical Research Center of Cancer, Tianjin Medical University Cancer Institute and Hospital, Tianjin 300060, China e-mail: prof_lianghan@126.com prognostic factor for GC patients after surgery. GC should be treated by specialized surgeons in large-volume centers.

Keywords Gastric carcinoma - Surgeon specialization · Prognosis · Recurrence

\section{Introduction}

Radical gastrectomy with D2 lymph node dissection has become increasingly regarded as the standard surgical procedure for most patients with operable gastric cancer. Even after R0 resection, the long-term outcome of gastric cancer remains poor. Although the prognosis of gastric cancer after surgery is mainly associated with tumor stage and other clinicopathological features, there is a growing consensus in the surgical literature that enhanced surgical technique and rich experience can improve outcomes for patients with curatively resected gastrointestinal cancer. Previous volume-outcome studies of patients with resectable gastric cancer have shown a positive association of surgical outcome with the hospital volume [1-4]. Compared with hospital volume, surgeon specialization can better predict surgical outcome in a given center. Many studies have affirmed the survival benefit for cancer patients treated by specialized surgeons [5-10]. With regard to gastric cancer, few studies focus on surgeon specialization.

We therefore used data of 967 patients with stage Ia-IIIc gastric cancer in a large-volume center to explore the impact of surgeon specialization on long-term outcome. Patients were categorized into two groups based on surgeon specialization, the specialized group (SG) and nonspecialized group (NSG). A one-to-one propensity score matching method was used to overcome bias due to the different 
distributions of covariates for the two groups. Clinicolpathological features, related prognostic factors and recurrence were analyzed.

\section{Materials and methods}

Patients and surgeons

A total of 1,695 patients with GC who underwent surgical resection at Tianjin Medical University Cancer Institute and Hospital between January 2003 and December 2007 were eligible for this study. Eligibility criteria included: (1) adenocarcinoma of the stomach, (2) patients with stage IIII disease who underwent gastrectomy with curative intent, (3) no history of gastrectomy or other malignancy and (4) no history of neoadjuvant chemotherapy. Ultimately, 976 patients were included in this study.

The 976 patients including 710 males $(72.7 \%)$ and 266 females $(27.3 \%)$. The ages ranged from 20 to 89 years, and the median age was 62 years. All patients were categorized into two groups according to the specialization of their surgeons: the specialized group (SG) and nonspecialized group (NSG). As a result, 261 patients were assigned to the SG and 715 patients to the NSG. Regarding surgeon specialization, specialized surgeons were defined as those: (1) from the Department of Gastric Cancer, (2) who had undergone professional training in gastrectomy and lymph node dissection in Japan, (3) whose annual gastric cancer surgeon volume was more than 50 and (4) with proven experience in D2 lymph node dissection confirmed by intraoperative photographs. As a result, only two surgeons met these conditions. The other 23 surgeons from nonspecialized units (including 8 from the Department of Hepatobiliary Cancer, 6 from the Department of Colorectal Cancer, 5 from the Department of Thoracic Cancer and 4 from the Department of Pancreatic Cancer) were defined as nonspecialized surgeons.

Evaluation of clinicopathological variables and survival

Clinicopathological features studied included gender, age, body mass index (BMI), tumor location, tumor size, Borrmann type, histology, depth of invasion, lymph node metastasis, metastatic lymph node ratio (rN), TNM stage, postoperative chemotherapy, surgical margin status, extent of lymphadenectomy, type of gastrectomy, total number of lymph nodes (LNs) dissected, postoperative complications and death. As patients in the two groups had different extents of node dissection and different node counts, which may result in stage migration, the metastatic lymph node ratio, which was not influenced by these factors and is reported to be a good indication of stage migration, was implemented in propensity score analysis [11, 12]. Using the log-rank test, we identified 0.1 and 0.5 as the best cutoff values for $\mathrm{rN}(\mathrm{rN} 0=0,0<\mathrm{rN} 1 \leq 0.1,0.1<\mathrm{rN} 2 \leq 0.5$, $\mathrm{rN} 3>0.5$ ). Negative resection margin was defined as microscopic complete resection without residual cancer cells in the margin. Positive resection margin was defined as microscopically determined residual cancer cells in the margin. Postoperative complications during hospitalization only included those directly associated with surgery, such as hemorrhage, wound dehiscence, anastomotic leak, pancreatic fistula, lymphatic fistula, and abdominal or wound infection. Postoperative mortality was defined as any deaths that occurred with 30 days of surgery.

The tumors were staged according to the 7th edition of the Union for International Cancer Control TNM Classification System, whereas lymphadenectomy and lymph node stations were defined according to the 3rd English Edition of the Japanese Classification of Gastric Carcinoma [13]. Tumors were classified into two groups based on histology: differentiated type, including papillary, well or moderately differentiated adenocarcinoma, and undifferentiated type, including poorly differentiated or undifferentiated adenocarcinoma, signet ring cell carcinoma and mucinous carcinoma.

\section{Follow-up}

The patients were followed up every 3 months up to 2 years after surgery, then every 6 months up to 5 years, then every year or until death. Physical examination, laboratory tests, chest X-ray and abdominal ultrasound (US) were performed at each visit, while endoscopy and abdominal computed tomography (CT) were obtained every 6 months. The overall survival rate was calculated from the day of surgery until time of death or final followup. The median follow-up was 31 months (range 0-103) and 33 months (range $0-103$ ) for the whole study series and the matched pair, respectively. The date of final follow-up was 30 December 2012.

\section{Statistical analysis}

For continuous variables, parametric analysis was performed using Student's $t$ test. Categorical variables were analyzed by means of the chi-square or Fisher's exact test. Overall survival curves were calculated using the KaplanMeier method based on the length of time between primary surgical treatment and final follow-up or death. The logrank test was used to assess statistical differences between curves. Independent prognostic factors were identified by the Cox proportional hazard regression model. To overcome bias due to the different distribution of covariates not associated with surgery for the two groups, a one-to-one 
Table 1 Clinicopathological features of GC patients who underwent gastrectomy with curative intent grouped by surgeon specialization: data are reported for the whole study series and for one-to-one propensity score matched pairs

\begin{tabular}{|c|c|c|c|c|c|c|}
\hline \multirow[t]{2}{*}{ Characteristics } & \multicolumn{3}{|c|}{ Whole study series } & \multicolumn{3}{|c|}{ Matched pairs (case-control method) } \\
\hline & $\begin{array}{l}\text { SG } \\
(n=261)\end{array}$ & $\begin{array}{l}\text { NSG } \\
(n=715)\end{array}$ & $p$ & $\begin{array}{l}\text { SG } \\
(n=261)\end{array}$ & $\begin{array}{l}\text { NSG } \\
(n=261)\end{array}$ & $p$ \\
\hline $\operatorname{Sex}$ & & & 0.265 & & & 0.381 \\
\hline Male/female & $183 / 78$ & $527 / 188$ & & $183 / 78$ & $192 / 69$ & \\
\hline Age at surgery (years) & & & 0.002 & & & 0.853 \\
\hline Mean $\pm \mathrm{SD}$ & $59.3 \pm 11.6$ & $61.9 \pm 11.5$ & & $59.3 \pm 11.6$ & $59.1 \pm 12.1$ & \\
\hline BMI $\left(\mathrm{kg} / \mathrm{m}^{2}\right)$ & & & 0.281 & & & 0.387 \\
\hline $\begin{array}{l}\text { Underweight/normal body } \\
\text { weight/overweight/obesity }\end{array}$ & 27/157/70/7 & $69 / 401 / 207 / 38$ & & $27 / 157 / 70 / 7$ & $34 / 150 / 64 / 13$ & \\
\hline Tumor location & & & $<0.001$ & & & 0.174 \\
\hline $\mathrm{L} / \mathrm{M} / \mathrm{U} /$ whole & $113 / 64 / 53 / 31$ & $267 / 132 / 246 / 70$ & & $113 / 64 / 53 / 31$ & $115 / 55 / 70 / 21$ & \\
\hline Tumor size & & & 0.711 & & & 0.930 \\
\hline$<5 \mathrm{~cm} / \geq 5 \mathrm{~cm}$ & $117 / 114$ & $311 / 404$ & & $117 / 114$ & $116 / 145$ & \\
\hline Borrmann type & & & 0.301 & & & 0.271 \\
\hline I/II/III/IV & 23/79/144/15 & $57 / 254 / 377 / 27$ & & 23/79/144/15 & 18/99/133/11 & \\
\hline Histology & & & 0.068 & & & 0.839 \\
\hline Differentiated/undifferentiated & $65 / 196$ & $221 / 494$ & & $65 / 196$ & $63 / 198$ & \\
\hline Depth of invasion & & & 0.565 & & & 0.409 \\
\hline$p \mathrm{~T} 1 / p \mathrm{~T} 2 / p \mathrm{~T} 3 / p \mathrm{~T} 4$ & $11 / 30 / 19 / 201$ & $19 / 85 / 44 / 567$ & & $11 / 30 / 19 / 201$ & 7/41/16/197 & \\
\hline $\mathrm{N}$ stage & & & 0.581 & & & 0.347 \\
\hline$p \mathrm{~N} 0 / p \mathrm{~N} 1 / p \mathrm{~N} 2 / p \mathrm{~N} 3$ & $103 / 41 / 65 / 52$ & 284/135/155/141 & & $103 / 41 / 65 / 52$ & $117 / 33 / 53 / 58$ & \\
\hline rN (metastatic lymph node ratio) & & & 0.020 & & & 0.326 \\
\hline $\mathrm{rN} 0 / \mathrm{rN} 1 / \mathrm{rN} 2 / \mathrm{rN} 3$ & $103 / 45 / 75 / 38$ & 284/79/202/150 & & $103 / 45 / 75 / 38$ & $117 / 32 / 70 / 42$ & \\
\hline$p$ TNM stage & & & 0.526 & & & 0.858 \\
\hline I/II/IIIa/IIIb/IIIc & $34 / 80 / 34 / 58 / 55$ & $80 / 226 / 123 / 148 / 138$ & & 34/80/34/58/55 & $38 / 86 / 27 / 55 / 55$ & \\
\hline Chemotherapy & & & 0.341 & & & 0.418 \\
\hline Yes/no & $156 / 105$ & $403 / 312$ & & $156 / 105$ & $165 / 96$ & \\
\hline Average LNs retrieval & & & $<0.001$ & & & $<0.001$ \\
\hline Mean \pm SD & $22.7 \pm 12.4$ & $12.9 \pm 8.3$ & & $22.7 \pm 12.4$ & $13.3 \pm 8.4$ & \\
\hline LNs retrieval & & & $<0.001$ & & & $<0.001$ \\
\hline$>15 / \leq 15$ & 198/63 & $226 / 489$ & & $198 / 63$ & $91 / 170$ & \\
\hline Extent of lymphadenectomy & & & $<0.001$ & & & $<0.001$ \\
\hline$\geq \mathrm{D} 2 /<\mathrm{D} 2$ & $217 / 44$ & $194 / 521$ & & $217 / 44$ & $77 / 184$ & \\
\hline Type of gastrectomy & & & $<0.001$ & & & 0.002 \\
\hline Total/subtotal & 98/173 & $143 / 572$ & & 98/173 & $56 / 205$ & \\
\hline Surgical margin status & & & 0.096 & & & 0.566 \\
\hline Negative/positive & $248 / 13$ & $657 / 58$ & & $248 / 13$ & $245 / 16$ & \\
\hline Postoperative complications & & & 0.089 & & & 0.167 \\
\hline Present/absent & $22 / 239(8.4 \%)$ & $39 / 676(5.8)$ & & $22 / 239$ & $14 / 247$ & \\
\hline Postoperative mortality & & & 0.764 & & & 0.315 \\
\hline Present/absent & $3 / 258$ & $10 / 705$ & & $3 / 258$ & $1 / 260$ & \\
\hline
\end{tabular}

$B M I$ body mass index

Underweight: $\mathrm{BMI}<18$; normal body weight: $18 \leq \mathrm{BMI}<24$; overweight: $24 \leq \mathrm{BMI}<28$; obesity: $\mathrm{BMI} \geq 28$

match was applied using propensity score analysis. Variables involved in the propensity model were sex, age, BMI, tumor location, tumor size, Borrmann type, histology, depth of invasion, $\mathrm{N}$ stage, $\mathrm{rN}$, TNM stage and postoperative chemotherapy. Operative factors including surgical margin status, extent of gastrectomy, type of gastrectomy, 
total number of lymph nodes (LNs) dissected, postoperative complications and death were not entered in the propensity model. $p<0.050$ was considered statistically significant. The statistical analysis was performed using the statistical analysis program package SPSS 18.0 (SPSS, Chicago, IL, USA).

\section{Results}

Clinicopathological features and postoperative outcome of the whole study series

Of the 976 GC patients who underwent gastrectomy, 261 were operated on by specialized surgeons in comparison to 715 patients operated on by nonspecialized surgeons. Nine hundred five patients had a R0 resection, and 71 patients ended up with an R1 resection. Four hundred eleven patients underwent D2 or greater lymph node dissection, and 559 patients received postoperative adjuvant chemotherapy with 5-fluorouracil, leucovorin and oxaliplatin.

The patients were categorized into two groups according to their surgeon type. Clinicopathologic variables were compared between the two groups as shown in Table 1 . There were no statistical differences in sex, BMI, tumor size, Borrmann type, histology, depth of invasion, N stage, TNM stage, chemotherapy, surgical margin status, postoperative morbidity and mortality between the two groups, whereas patients in the SG had a larger proportion of $\mathrm{LN}$ retrieval $>15$ ( 75.9 vs. $31.6 \%, p<0.001$ ), greater number of lymph node retrieval $(22.7 \pm 12.4$ vs. $12.9 \pm 8.3$, $p<0.001$ ), higher ratio of $\geq \mathrm{D} 2$ lymph node dissection (83.1 vs. $27.1 \%, p<0.001)$ and higher rate of total gastrectomy ( 33.7 vs. $20.0 \%, p<0.001$ ), but lower incidence of tumors invading the upper third of the stomach (20.3 vs. $34.4 \%, p<0.001)$, younger mean age $(59.3 \pm 11.6$ vs. $61.9 \pm 11.5, p=0.002)$ than in the NSG.

In the entire study population, patients in the SG had a significantly higher OS rate than those in the NSG (5-year OS: 50.7 vs. $37.2 \%, p=0.001$ ) (Fig. 1a). The results of the univariate and multivariate survival analysis are shown in Table 2. A total of eight factors evaluated in the univariate analysis had a significant effect on survival: age $(\geq 70)$, tumor location, tumor size $(<5$ vs. $\geq 5 \mathrm{~cm}$ ), Borrmann type (type III and IV), histology, TNM stage, postoperative chemotherapy and surgeon specialization. In multivariate analysis, age $(\geq 70)$, tumor location (invading $2 / 3$ or more of the stomach), tumor size, Borrmann type (III and IV), histology, TNM stage and surgeon specialization (hazard ratio was 1.489 for- NSG, $p<0.001$ ) were found to be independent prognostic factors for OS. With the strata analysis, significant prognostic differences between the two
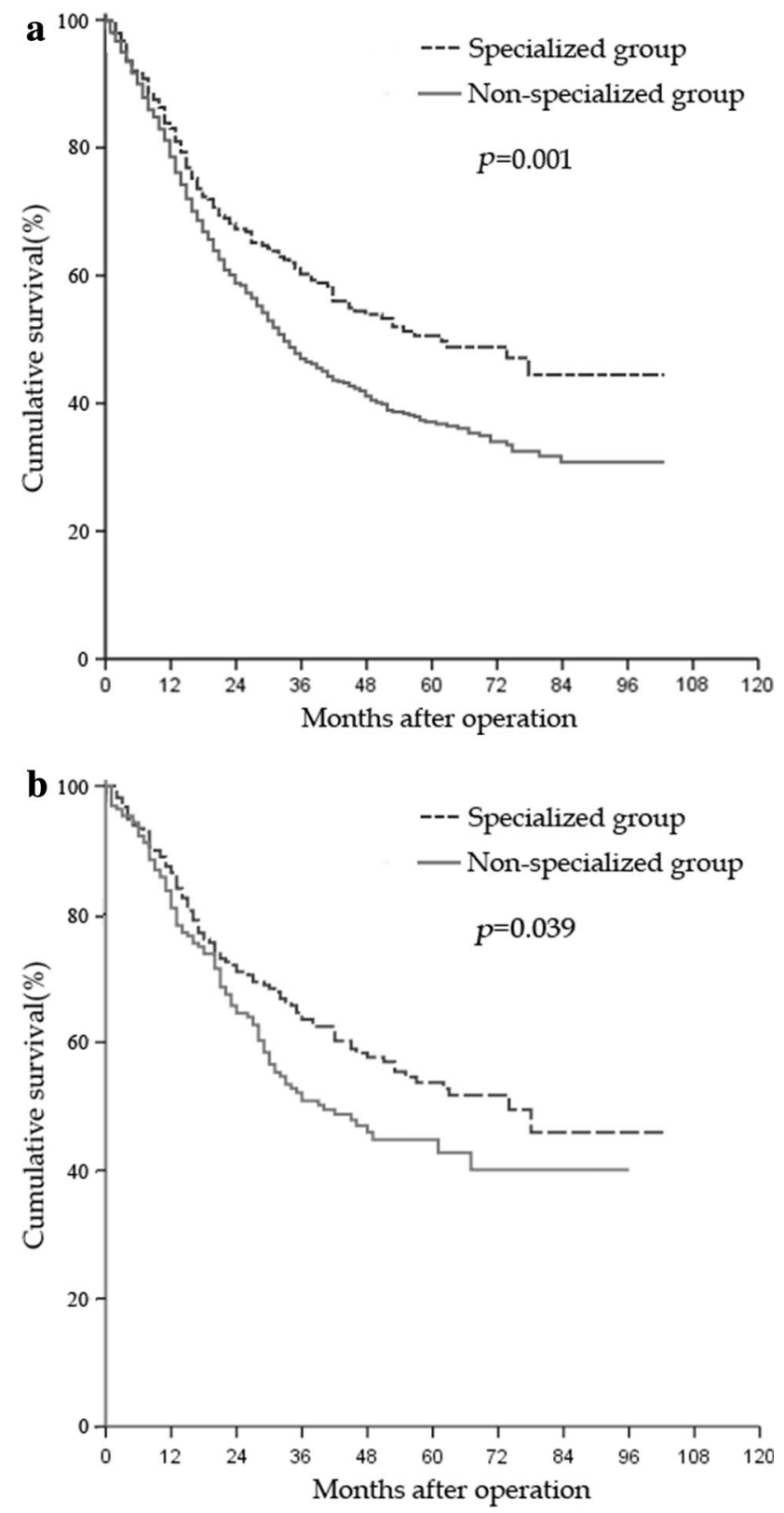

Fig. 1 Prognosis of the whole study series who underwent surgery for GC. Patients were categorized into two groups based on their surgeon type: the specialized group (SG) and nonspecialized group (NSG). a Survival curve for all patients; the 5-year OS rate was 50.7 and $37.2 \%$ for the SG and NSG, respectively $(p=0.001)$. b Survival curve for patients receiving $\geq \mathrm{D} 2$ dissection; the 5-year OS rate was 53.7 and $44.8 \%$ for the SG and NSG, respectively $(p=0.039)$

groups were only observed in patients at stage II, IIIa and IIIb or N0-2 or rN0-2 (Table 3). The numbers of lymph nodes retrieval in the $\geq \mathrm{D} 2$ resection performed in the $\mathrm{SG}$ and NSG were $24.2 \pm 12.2$ and $16.7 \pm 9.7$, respectively $(p=0.026)$. D2 or greater than $\mathrm{D} 2$ lymph node dissection performed by specialized surgeons demonstrated a better prognosis than that performed by nonspecialized surgeons (5-year OS: 53.7 vs. $44.8 \%, p=0.039$ ) (Fig. 1b). 
Table 2 Univariate and multivariate survival analysis of GC patients in the whole study series

\begin{tabular}{|c|c|c|c|c|c|c|}
\hline \multirow[t]{2}{*}{ Characteristics } & \multirow[t]{2}{*}{$n(\%)$} & \multirow[t]{2}{*}{ 5-year OS (\%) } & \multicolumn{2}{|l|}{ Univariate analysis } & \multicolumn{2}{|l|}{ Multivariate analysis } \\
\hline & & & HR (95\%CI) & $p$ & HR $(95 \% \mathrm{CI})$ & $p$ \\
\hline \multicolumn{7}{|l|}{ Sex } \\
\hline Male & $710(72.7)$ & 39.2 & 1 (ref) & & & \\
\hline Female & $266(27.3)$ & 44.7 & $0.898(0.741-1.087)$ & 0.269 & & \\
\hline \multicolumn{7}{|c|}{ Age at surgery (years) } \\
\hline$\leq 49$ & $174(17.8)$ & 51.2 & 1 (ref) & & 1 (ref) & \\
\hline $50-70$ & $519(53.2)$ & 45.8 & $1.206(0.932-1.560)$ & 0.154 & $1.262(0.970-1.641)$ & 0.083 \\
\hline$\geq 70$ & $283(29.0)$ & 25.8 & $1.949(1.492-2.546)$ & $<0.001$ & $1.795(1.349-2.389)$ & $<0.001$ \\
\hline \multicolumn{7}{|l|}{ BMI $\left(\mathrm{kg} / \mathrm{m}^{2}\right)$} \\
\hline$<18$ & $96(9.8)$ & 34.2 & 1 (ref) & & & \\
\hline $18 \leq \mathrm{BMI}<24$ & $558(57.2)$ & 42.6 & $0.849(0.645-1.119)$ & 0.245 & & \\
\hline $24 \leq \mathrm{BMI}<28$ & 277 (28.4) & 39.1 & $0.943(0.701-1.267)$ & 0.696 & & \\
\hline$\geq 28$ & 45 (4.6) & 44.1 & $0.793(0.498-1.264)$ & 0.330 & & \\
\hline \multicolumn{7}{|l|}{ Tumor location } \\
\hline Lower third & $380(38.9)$ & 51.5 & 1 (ref) & & 1 (ref) & \\
\hline Middle third & $196(20.1)$ & 39.5 & $1.531(1.209-1.938)$ & $<0.001$ & $1.250(0.982-1.592)$ & 0.070 \\
\hline Upper third & 299 (30.6) & 34.7 & $1.580(1.283-1.946)$ & $<0.001$ & $1.158(0.929-1.443)$ & 0.191 \\
\hline $2 / 3$ or more & $101(10.3)$ & 18.0 & $2.746(2.080-3.624)$ & $<0.001$ & $1.386(1.020-1.883)$ & 0.037 \\
\hline \multicolumn{7}{|l|}{ Tumor size } \\
\hline$<5 \mathrm{~cm}$ & 428 (43.9) & 52.9 & 1 (ref) & & 1 (ref) & \\
\hline$\geq 5 \mathrm{~cm}$ & $548(56.1)$ & 31.4 & $1.868(1.563-2.232)$ & $<0.001$ & $1.284(1.065-1.594)$ & 0.009 \\
\hline \multicolumn{7}{|l|}{ Borrmann type } \\
\hline I & $80(8.2)$ & 60.1 & 1 (ref) & & 1 (ref) & \\
\hline II & $333(34.1)$ & 46.9 & $1.419(0.961-2.093)$ & 0.078 & $1.259(0.849-1.868)$ & 0.251 \\
\hline III & $521(53.4)$ & 35.7 & $1.948(1.339-2.835)$ & $<0.001$ & $1.477(1.008-2.165)$ & 0.045 \\
\hline IV & $42(4.3)$ & 16.0 & $3.516(2.142-5.772)$ & $<0.001$ & $2.821(1.662-4.787)$ & $<0.001$ \\
\hline \multicolumn{7}{|l|}{ Histology } \\
\hline Differentiated & $286(29.3)$ & 48.7 & 1 (ref) & & 1 (ref) & \\
\hline Undifferentiated & $690(70.7)$ & 37.2 & $1.376(1.135-1.667)$ & 0.001 & $1.234(1.009-1.509)$ & 0.040 \\
\hline \multicolumn{7}{|l|}{$p$ TNM stage } \\
\hline I & $114(11.7)$ & 78.7 & 1 (ref) & & 1 (ref) & \\
\hline II & $306(31.4)$ & 54.4 & $2.376(1.524-3.705)$ & $<0.001$ & $2.059(1.315-3.224)$ & 0.002 \\
\hline IIIa & $157(16.1)$ & 38.1 & $4.088(2.587-6.459)$ & $<0.001$ & $3.224(2.017-5.155)$ & $<0.001$ \\
\hline IIIb & $206(21.1)$ & 29.6 & $4.990(3.205-7.769)$ & $<0.001$ & $3.856(2.448-6.074)$ & $<0.001$ \\
\hline IIIc & $193(19.8)$ & 10.7 & $10.001(6.441-15.528)$ & $<0.001$ & $7.571(4.803-11.932)$ & $<0.001$ \\
\hline \multicolumn{7}{|l|}{ Chemotherapy } \\
\hline Yes & $559(60.6)$ & 41.7 & 1 (ref) & & 1 (ref) & \\
\hline No & 317 (39.4) & 39.4 & $1.241(1.048-1.470)$ & 0.012 & $1.140(0.955-1.362)$ & 0.147 \\
\hline \multicolumn{7}{|c|}{ Surgeon specialization } \\
\hline SG & $261(26.7)$ & 50.7 & 1 (ref) & & 1 (ref) & \\
\hline NSG & $715(73.3)$ & 37.2 & $1.417(1.155-1.738)$ & 0.001 & $1.489(1.207-1.837)$ & $<0.001$ \\
\hline
\end{tabular}

Results after propensity score matching

We analyzed 261 patients in each group, who were selected by one-to-one matching using propensity scores. Characteristics after the propensity score analysis are shown in Table 1. Two hundred sixty-one of the 715 patients in the
NSG were matched with 261 patients in the SG after covariate adjustment. All covariates that possibly affected OS but were not associated with surgery in the whole study series were equally distributed over the two matched groups. The rN stage was also entered in matching to overcome the stage migration resulting from the different 
Table 3 Strata survival analysis of the GC patients according to the surgeon specialization: data are reported for the whole study series and for one-to-one propensity score matched pairs

\begin{tabular}{|c|c|c|c|c|c|c|}
\hline \multirow[t]{2}{*}{ Tumor stage } & \multicolumn{3}{|c|}{$\begin{array}{l}5 \text {-year OS for whole study } \\
\text { series }(\%)\end{array}$} & \multicolumn{3}{|c|}{$\begin{array}{l}5 \text {-year OS for matched } \\
\text { pairs }(\%)\end{array}$} \\
\hline & SG & NSG & $p$ & SG & NSG & $p$ \\
\hline \multicolumn{7}{|l|}{$\mathrm{N}$ stage } \\
\hline$p \mathrm{~N} 0$ & 71.1 & 59.8 & 0.041 & 71.1 & 61.2 & 0.142 \\
\hline$p \mathrm{~N} 1$ & 60.2 & 34.4 & 0.012 & 60.2 & 44.8 & 0.044 \\
\hline$p \mathrm{~N} 2$ & 44.7 & 22.3 & 0.002 & 44.7 & 25.8 & 0.009 \\
\hline$p \mathrm{~N} 3$ & 12.3 & 10.5 & 0.908 & 12.3 & 8.0 & 0.748 \\
\hline \multicolumn{7}{|l|}{ rN stage } \\
\hline rNO & 71.1 & 59.8 & 0.041 & 71.1 & 61.2 & 0.142 \\
\hline rN1 & 53.9 & 41.5 & 0.043 & 53.9 & 38.6 & 0.033 \\
\hline $\mathrm{rN} 2$ & 43.4 & 25.3 & 0.047 & 43.4 & 23.8 & 0.027 \\
\hline rN3 & 8.5 & 8.5 & 0.547 & 8.5 & 8.8 & 0.322 \\
\hline \multicolumn{7}{|l|}{ TNM stage } \\
\hline I & 79.0 & 78.9 & 0.763 & 79.0 & 75.9 & 0.579 \\
\hline II & 67.3 & 50.3 & 0.019 & 67.3 & 50.4 & 0.062 \\
\hline IIIa & 61.7 & 31.7 & 0.008 & 61.7 & 35.6 & 0.046 \\
\hline IIIb & 42.6 & 24.3 & 0.014 & 42.6 & 32.9 & 0.049 \\
\hline IIIc & 13.6 & 9.4 & 0.590 & 13.6 & 8.6 & 0.942 \\
\hline \multicolumn{7}{|c|}{ Extent of lymphadenectomy } \\
\hline$\geq \mathrm{D} 2$ & 53.7 & 44.8 & 0.039 & 53.7 & 46.1 & 0.041 \\
\hline$<\mathrm{D} 2$ & 36.0 & 35.2 & 0.686 & 36.0 & 37.7 & 0.577 \\
\hline
\end{tabular}

extents of node dissection and different node counts. Matched patients in the SG had a similar sex ratio, mean age at surgery, BMI, tumor location, tumor size, Borrmann type, histology, depth of invasion, $\mathrm{N}$ stage, rN, TNM stage and chemotherapy as those of the matched patients in the NSG. Although the covariates associated with surgery were not entered in the matching, there were no significant differences in the surgical margin status, postoperative morbidity or mortality between the two groups. However, even after matching, patients in the SG still had a larger proportion of $\mathrm{LN}$ retrieval $>15$ (75.9 vs. $34.9 \%, p<0.001)$, higher ratio of $\geq \mathrm{D} 2$ lymph node dissection (83.1 vs. $29.5 \%, p<0.001)$, higher rate of total gastrectomy (37.5 vs. $21.5 \%, p=0.002$ ) and more lymph node retrieval $(22.7 \pm 12.4$ vs. $13.3 \pm 8.4, p<0.001)$.

In the matched study series, the OS rate was also significantly higher in the SG than in the NSG. The 5-year OS rates were $50.7 \%$ in the SG and $39.8 \%$ in the NSG, respectively ( $p=0.029$ ) (Fig. 2). With the strata analysis, patients in the SG had a significantly higher 5-year OS than those in the NSG at stage IIIa-b, N1-2 or rN1-2. Similar to the whole study series, for patients receiving $\geq \mathrm{D} 2$ lymph node dissection, those in the SG had a significantly higher OS than those in the NSG (5-year OS: 53.7 vs. $46.1 \%$, $p=0.041)$.

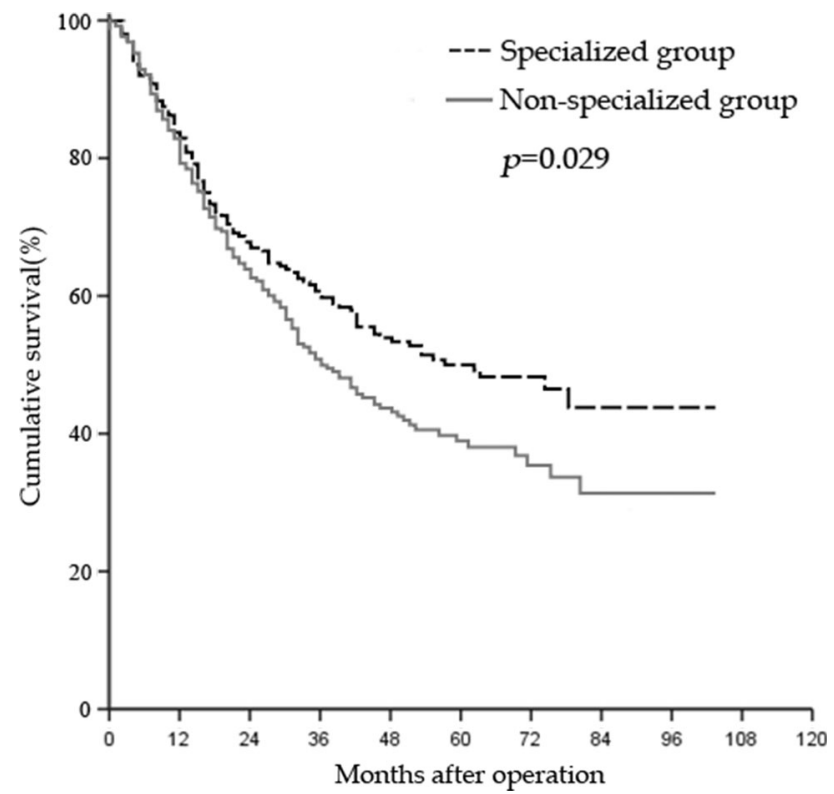

Fig. 2 Prognosis of the matched study series of 522 patients who underwent surgery for gastric cancer. The 5-year OS rate was $50.7 \%$ for patients operated on by specialized surgeons and $39.8 \%$ for those by nonspecialized surgeons, respectively $(p=0.029)$

Table 4 Patterns of initial recurrence in the whole study series

\begin{tabular}{lccl}
\hline Patterns of recurrence & SG $(\mathrm{n}=261)$ & NSG $(\mathrm{n}=715)$ & $p$ \\
\hline Locoregional & $25(9.6)$ & $126(17.6)$ & 0.002 \\
Lymph node & $10(3.8)$ & $54(7.6)$ & 0.038 \\
Gastric stump & $7(2.7)$ & $36(5.0)$ & 0.113 \\
Anastomosis & $4(1.5)$ & $16(2.2)$ & 0.491 \\
Gastric bed & $4(1.5)$ & $20(2.8)$ & 0.259 \\
Peritoneal & $39(14.9)$ & $98(13.7)$ & 0.623 \\
Hematogenous & $28(10.7)$ & $79(11.0)$ & 0.887 \\
Combined & $24(9.2)$ & $95(13.3)$ & 0.084 \\
Overall recurrence & $116(44.4)$ & $398(55.7)$ & 0.002 \\
\hline
\end{tabular}

Recurrence in the whole study series

The patterns and incidence of recurrence in the whole study series are shown in Table 4. Although there were no significant differences in peritoneal, hematogenous and combined recurrence between the two groups, patients in the NSG had a significantly higher overall recurrence rate than those in the SG (55.7 vs. $44.4 \%, p=0.002)$. The proportion of locorregional recurrence was greater in the NSG (17.6 vs. $9.6 \%, p=0.002$ ). Locoregional recurrence was the main recurrence type followed by peritoneal and hematogenous recurrence for patients in the NSG. For patients with locoregional recurrence, lymph node recurrence was greater in the NSG (7.6 vs. $3.8 \%, p=0.038)$, while other recurrence types, including gastric stump, 
anastomosis and gastric bed recurrence, showed no significant differences between the two groups.

\section{Discussion}

This study demonstrates that GC patients operated on by a specialized surgeon who comes from a gastric oncology unit and has undergone professional training in gastrectomy and lymph node dissection were associated with improved survival and lower locoregional recurrence rates compared to those operated on by a nonspecialized surgeon; surgeon specialization was an independent prognostic factor for GC patients after surgery on multivariate analysis.

Previous studies have affirmed the positive influence of surgeon specialty on survival for various types of malignancies. Dooley et al. [8] reported the OS and disease-free survival of breast cancer were significantly improved if the surgery was performed by surgical oncologists rather than general surgeons. Read et al. [9] demonstrated that surgeon specialty contributed to prolonged disease-free survival and a higher rate of local control for colorectal cancer, and the background of the surgeon (colorectal or noncolorectal) was an independent predictor of disease-free survival. Barbas et al. [10] found the OS of colon cancer patients was significantly improved if the operation was performed by a specialty-trained surgeon, and surgeon specialization was an independent predictor of improved OS. They further discovered worse survival for stage II patients was associated with inadequate lymphadenectomy performed by non-specialty-trained surgeon. All of these studies highlighted the importance of specialty treatment in cancer surgery. Compared with these carcinomas, the D2 dissection procedure in gastric cancer surgery is more complex and requires a significant degree of training and expertise. The NCCN (National Comprehensive Cancer Network) guidelines emphasize that D2 dissection should be performed by experienced surgeons in high volume centers [14]. However, until now. few studies have focused on professional treatment in gastric cancer.

Several studies suggested that GC surgery should be performed in specialized centers as they found the rate of mortality and morbidity was significantly lower if GC patients were operated on by surgeons with high caseloads or coming from specialized units [15-17]. Our result was different from these studies. We found no significant differences in postoperative complications and deaths between the SG and NSG, even after propensity score matching. This was consistent with the research conducted by $\mathrm{Yu}$ et al. [18], which revealed no statistical differences in surgical mortality between patients who underwent surgery by a specialized surgeon and those by a general surgeon. In the present study, the ratio of $\geq \mathrm{D} 2$ dissection was merely $27.1 \%$ in the NSG compared to $83.1 \%$ in the SG. Nonspecialized surgeons were usually reluctant to performed D2 dissection as it was associated with higher postoperative mortality and morbidity, proved by previous studies $[19,20]$. We think the low rate of $\geq \mathrm{D} 2$ dissection in the NSG may account for the low incidence of mortality and morbidity after surgery.

With regard to the influence of surgeon specialization on the long-term outcome of GC, these studies did not give further illustration. So far, there is no clear definition of a specialized GC surgeon. Only Yu et al. [18] defined a specialized GC surgeon as one who had carried out 2 or more consecutive years of surgical practice, with caseloads of more than 50 per year. They demonstrated the 5-year OS was significantly improved for GC patients operated on by high-volume surgeons with 2 or more consecutive years of surgical practice, and the 5-year OS rate was 66.8 and $58.7 \%$ for high-volume and low-volume surgeons, respectively ( $p=0.0004)$. Bachmann et al. [21] reported that the risk of death decreased by $7 \%$ for each increase of ten patients in hospitals' annual caseloads ( $p=0.009)$. In the present study, a specialized surgeon was defined as one from a gastric oncology unit who had undergone professional training in D2 lymphadenctomy and with gastric cancer caseloads of no less than 50 per year, and surgeon specialization was found to be an independent prognostic factor on multivariate analysis (hazard ratio 1.489, $95 \%$ CI: $1.207-1.837, p<0.001)$. We further discovered that patients in the SG had a significantly higher 5-year OS rate than those in the NSG even after propensity score matching (5-year OS: 50.7 vs. $39.8 \%, p=0.029$ ). In the stratified analysis, a significant improvement in survival was seen for IIIa-b, N1-2 or rN1-2 stages with respect to NSG, but this effect disappeared for stage I and IIIc patients in both the whole study series and the matched pairs. Schwarz et al. [22] found that patients who had more than $15 \mathrm{~N} 2$ nodes and more than $20 \mathrm{~N} 3$ nodes examined had the best longterm survival outcomes. A study from the USA also suggested the positive impact of total lymph node count on survival after gastrectomy for GC [23]. From this point of view, the worse survival of the NSG may be due to inadequate lymphadenectomy as the average lymph node retrieval was merely $12.9 \pm 8.3$ and $<$ D2 dissection accounted for $72.9 \%$ in the operations performed by nonspecialized surgeons. A more interesting result in the present study is that for patients receiving $\geq \mathrm{D} 2$ dissection, those operated on by specialized surgeons still demonstrated significantly better survival than those operated on by nonspecialized surgeons after matching (5-year OS: 53.7 vs. $46.1 \%, p=0.041)$. D2 dissection in gastric cancer surgery is considered to be a complex procedure and requires a significant degree of training and expertise. 
Nonspecialized surgeons without specialized training are not familiar with the technique and have not reached the plateau of the learning curve for D2 lymphadenectomy. The mean number of lymph nodes harvested in $\geq \mathrm{D} 2$ resection performed in the NSG was merely $16.7 \pm 9.7$. Therefore, these D2 dissections could not have been as complete as those performed by specialized surgeons; some locoregional lymph nodes were more or less left without being removed. This is possibly the main reason for the poorer outcome of D2 dissection performed by nonspecialized surgeons.

To verify the incompleteness of lymph node dissection performed by nonspecialized surgeons, the recurrence data of the whole study series were also analyzed. We found that the major recurrence pattern for NSG was locoregional, while for SG it was peritoneal and hematogenous, and patients in the NSG had a significantly higher lymph node recurrence rate than those in the SG (7.6 vs. $3.8 \%$, $p=0.038$ ). The 15 -year follow-up results of the randomized nationwide Dutch D1D2 trial suggested that a D2 dissection decreased locoregional recurrence compared with limited D1 surgery (25 vs. $41 \%$ ) [24]. Our result was somewhat consistent with the trial as in the SG $84.1 \%$ of patients underwent $\mathrm{a} \geq \mathrm{D} 2$ dissection and in the NSG $72.9 \%$ of patients received a $<\mathrm{D} 2$ surgery. We considered that incomplete lymphadenectomy resulted in residual locoregional lymph nodes, and thus a higher rate of locoregional recurrence, especially lymph node recurrence.

In conclusion, GC patients operated on by a specialized surgeon tended to have a higher OS and lower locoregional recurrence rate with acceptable postoperative mortality and morbidity than those operated on by a nonspecialized surgeon. Surgeon specialization was an independent prognostic factor for GC after surgery. It is suggested that GC patients should be treated by specialized surgeons in a large-volume center. Professional training, especially standard lymphadenectomy, was necessary for GC surgeons.

Conflict of interest We state no conflict of interest or funding sources exit related to this manuscript.

\section{References}

1. Nomura E, Tsukuma H, Ajiki W, Oshima A. Population-based study of relationship between hospital surgical volume and 5-year survival of stomach cancer patients in Osaka. Japan. Cancer Sci. 2003;94(11):998-1002.

2. Damhuis RA, Meurs CJ, Dijkhuis CM, Stassen LP, Wiggers T. Hospital volume and post-operative mortality after resection for gastric cancer. Eur J Surg Oncol. 2002;28(4):401-5.

3. Bachmann MO, Alderson D, Edwards D, Wotton S, Bedford C, Peters TJ, Harvey IM. Cohort study in South and West England of the influence of specialization on the management and outcome of patients with oesophageal and gastric cancers. Br J Surg. 2002;89(7):914-22.
4. Wenner J, Zilling T, Bladström A, Alvegård TA. The influence of surgical volume on hospital mortality and 5-year survival for carcinoma of the oesophagus and gastric cardia. Anticancer Res. 2005;25(1B):419-24.

5. Bachmann MO, Alderson D, Peters TJ, Bedford C, Edwards D, Wotton S, Harvey IM. Influence of specialization on the management and outcome of patients with pancreatic cancer. Br J Surg. 2003;90(2):171-7.

6. Earle CC, Schrag D, Neville BA, Yabroff KR, Topor M, Fahey A, Trimble EL, Bodurka DC, Bristow RE, Carney M, Warren JL. Effect of surgeon specialty on processes of care and outcomes for ovarian cancer patients. J Natl Cancer Inst. 2006;98(3):172-80.

7. Smith JA, King PM, Lane RH, Thompson MR. Evidence of the effect of 'specialization' on the management, surgical outcome and survival from colorectal cancer in Wessex. $\mathrm{Br} \mathrm{J}$ Surg. 2003;90(5):583-92.

8. Dooley WC, Bong J, Parker J. Mechanisms of improved outcomes for breast cancer between surgical oncologists and general surgeons. Ann Surg Oncol. 2011;18(12):3248-51.

9. Read TE, Myerson RJ, Fleshman JW, Fry RD, Birnbaum EH, Walz BJ, Kodner IJ. Surgeon specialty is associated with outcome in rectal cancer treatment. Dis Colon Rectum. 2002;45(7):904-14.

10. Barbas AS, Turley RS, Mantyh CR, Migaly J. Effect of surgeon specialization on long-term survival following colon cancer resection at an NCI-designated cancer center. J Surg Oncol. 2012;106(3):219-23.

11. Zhou Y, Zhang J, Cao S, Li Y. The evaluation of metastatic lymph node ratio staging system in gastric cancer. Gastric Cancer. 2013;16(3):309-17.

12. Kong SH, Lee HJ, Ahn HS, Kim JW, Kim WH, Lee KU, Yang HK. Stage migration effect on survival in gastric cancer surgery with extended lymphadenectomy: the reappraisal of positive lymph node ratio as a proper N-staging. Ann Surg. 2012;255(1):50-8.

13. Japanese Classification of Gastric Carcinoma. 3rd English edn. Japanese Gastric Cancer Association. Gastric Cancer. 2011;14(2):101-12.

14. NCCN Clinical Practice Guidelines in Oncology for Gastric Cancer. Version 2. 2013.

15. Sah BK, Zhu ZG, Chen MM, Xiang M, Chen J, Yan M, Lin YZ. Effect of surgical work volume on postoperative complication: superiority of specialized center in gastric cancer treatment. Langenbecks Arch Surg. 2009;394(1):41-7.

16. Baré M, Cabrol J, Real J, Navarro G, Campo R, Pericay C, Sarría A. In-hospital mortality after stomach cancer surgery in Spain and relationship with hospital volume of interventions. BMC Public Health. 2009;9:312.

17. Portanova M, Vargas F, Lombardi E, Mena V, Carbajal R, Palacios N, Orrego J. Results of specialization in the surgical treatment of gastric cancer in Peru. Gastric Cancer. 2007;10(2):92-7.

18. Yu W, Yun YK, Whang I, Choi GS. The surgeon's expertiseoutcome relationship in gastric cancer surgery. Cancer Res Treat. 2005;37(3):143-7.

19. Bonenkamp JJ, Hermans J, Sasako M, van de Velde CJ, Welvaart K, Songun I, Meyer S, Plukker JT, Van Elk P, Obertop H, Gouma DJ, van Lanschot JJ, Taat CW, de Graaf PW, von Meyenfeldt MF, von Tilanus H. Dutch gastric cancer group. Extended lymphnode dissection for gastric cancer. $N$ Engl $J$ Med. 1999;340(12):908-14.

20. Cuschieri A, Weeden S, Fielding J, Bancewicz J, Craven J, Joypaul V, Sydes M, Fayers P. Patient survival after D1 and D2 resections for gastric cancer: long-term results of the MRC randomized surgical trial. Surgical co-operative group. Br J Cancer. 1999;79(9-10):1522-30. 
21. Bachmann MO, Alderson D, Edwards D, Wotton S, Bedford C, Peters TJ, Harvey IM. Cohort study in South and West England of the influence of specialization on the management and outcome of patients with oesophageal and gastric cancers. Br J Surg. 2002;89(7):914-22.

22. Schwarz RE, Smith DD. Clinical impact of lymphadenectomy extent in resectable gastric cancer of advanced stage. Ann Surg Oncol. 2007;14(2):317-28.
23. Smith DD, Schwarz RR, Schwarz RE. Impact of total lymph node count on staging and survival after gastrectomy for gastric cancer: data from a large US-population database. J Clin Oncol. 2005;23(28):7114-24.

24. Songun I, Putter H, Kranenbarg EM, Sasako M, van de Velde CJ. Surgical treatment of gastric cancer: 15-year follow-up results of the randomised nationwide Dutch D1D2 trial. Lancet Oncol. 2010;11(5):439-49. 